\title{
Distribution Patterns of Severe Pediatric Trauma: Mandated vs. Non-Mandated Trauma Systems"
}

\author{
Raouf M. Afifi ${ }^{1,2 \#}$, Sameh S. Zaytoun ${ }^{3}$ \\ ${ }^{1}$ Community Health Department, International Management-Health Services Institute, Indianapolis, USA \\ ${ }^{2}$ Preventive Medicine Departments, Armed Forces Hospitals, Taif, KSA \\ ${ }^{3}$ Public Health Department, Faculty of Medicine, South Valley University, Qena, Egypt \\ Email: "raoufafifi@hotmail.com, raoufafifi@itm-hs.org
}

Received May 30, 2013; revised July 1, 2013; accepted July 10, 2013

Copyright (C) 2013 Raouf M. Afifi et al. This is an open access article distributed under the Creative Commons Attribution License, which permits unrestricted use, distribution, and reproduction in any medium, provided the original work is properly cited.

\begin{abstract}
Objective: To identify how hospital discharge data could discriminate the distribution patterns of high-risk trauma children in mandated and non-mandated trauma systems. Methods: Hospital discharge data of pediatric trauma patients 1 15 years of age in Florida (FL), USA - [a mature mandated trauma system with certified trauma centers (TCs)] and in Indiana (IN), USA - (an immature non-mandated trauma system) admitted both to trauma center (TC) and non-TC healthcare facilities were analyzed. The injury severity score (ISS) measurement was used to verify injury severities. Results: Analysis showed that the majority of admissions were mild injuries (ISS $=1$ - 8), [FL 70\%, IN 66\%, odds ratio (OR) 1.2, 95\% confidence interval (CI) 1.1, 1.3]. Florida trauma children (all severities) generally receive TC care more frequently than Indiana's (OR $=1.8$, CI $1.6-1.9)$. Particularly admission to TCs with severe (ISS $\geq 25)$ pelvic injury was greater in Florida (OR 3.5, CI 1.6 - 7.4). Florida, encountered some other severe injury mechanisms (motor vehicle accidents, falls) more frequently than Indiana (ORs and CI: 2.2, 1.5 - 3.3 and 3.1, 1.1 - 8.7, respectively). Conclusions: Hospital discharge data can demonstrate the expected patient distribution difference when comparing a mature trauma system with a voluntary evolving system. The level of maturity of the adopted trauma system often influences such difference.
\end{abstract}

Keywords: Child Injury; High Risk; Distribution Pattern; Trauma System; Mandated

\section{Introduction}

Injury represents the leading cause of death and disability among children and adolescents in the United States [1]. It was estimated that almost 16 million individuals below 20 years of age are evaluated for trauma every year [2]. 11 million children 4 - 15 years of age visit emergency departments every year in the US [3], $50 \%$ of whom are for injury [4]. In the latter group; over 189,000 require hospitalization due to moderate to severe injuries [5]. Compared to adults, children are more prone to accidental trauma, e.g., fall, motor vehicle accidents. At the trauma system maturity level, differences in the patterns of care of high-risk patients exist. Even those states without formal trauma systems may have developed attributes of systematic care (e.g., pre-hospital triage protocols, trauma prevention programs). Traditionally, non-mandated versus mandated pre-hospital trauma triage systems which

\footnotetext{
${ }^{*}$ Congresses: None; Funding: Self-funded; Conflicts of interest: None.

${ }^{*}$ Corresponding author.
}

are thought to differentiate in that high-risk patients in the former are transported directly to a level I/II TCs to receive specialized care while in the latter they are transported to the nearest emergency department. Mann, et al. [6] in a comparison of the Oregon and Washington trauma systems concluded that there was a bias in favor of admitting more serious patients to Level I/II TCs in Oregon that adopts a mandated trauma system. Since ongoing performance improvement is an important component of trauma system development, we believe that the best measures of the stability and performance of a state or regional trauma system and the provision of its services are through the inclusion of all injured patients hospitalized from a specific area. To this end, a state's trauma registry development should include data from all hospitals caring for injured patients. Nonetheless, trauma registries are often used to obtain relatively comprehensive injury data for a few facilities but this source of information may exclude patients who are treated in hospitals that are not designated as a TC. Therefore, health 
services researchers have used hospital discharge data and claims data in evaluating the standard and quality of trauma systems. However, their usability is often limited due to the lack of complete or accurate information [7]. The American College of Surgeons Committee on Trauma (ACS-COT) audits TCs through its verification program; their performances can be assessed either solely or as a member of a group of TCs within a state. Centers can also be evaluated using population based data available from a statewide trauma registry or from another source of statewide inpatient admissions information.

Generally, the evolution of trauma systems in the future will involve key components, such as the reliability of using a hospital discharge database, and an assessment of pre-hospital care services. In 2002, there were 1154 general TCs in the United States, including 190 level I TCs and 263 level II TCs [8], and the number of level I and II TCs per million population ranged from 0.19 to 7.8. According to the 2000 US census, the total population of Florida was 15,982,378 and that of Indiana 6,080,485 [9]. Ever since, Florida trauma system, with 216 hospitals, had been in existence for approximately 10 years with 20 level I/II TCs and operated under mandated triage guidelines. Indiana, on the other hand, did not have a formal trauma system or mandated triage guidelines among its 117 hospitals and four level I/II TCs. The Indiana trauma system had three "evolving" TCs that were in various stages of participation in the ACS-trauma center consultation-verification program. Given the important geographic location of these evolving centers, we included them as "TC" in this report, bringing the Indian trauma center total to seven. Reports indicate that injury and violence are serious threats to the health and well-being of children and adolescents in the United States [10]. Of those who aged 1 to 17 and who experienced some form of physical injury, over 200,000 require hospitalization, and more than 92,000 children become permanently disabled $[11,12]$. Trauma system development remains a work in progress aided by a trauma system assessment program sponsored by the ACS that was designed to facilitate development of state-based trauma systems. It was not until after the mid-1960s when a growing public interest in improving care of the injured became manifest. Since then, much progress has been made in developing systems of care that strive to reduce the burden of injury. In essence, trauma care systems deliver a continuum of pre-hospital, acute care, and rehabilitation services. Yet, despite their public health mission, only some comprehensive regional systems of trauma care have been put into place by a number of states, although some of the system elements are present in many other states and communities [13]. A federal government's response then came through the work of numerous agencies in nearly all cabinet-level departments. Subsequently, a Title XII of the Public Health Service Act (PHSA) of the Trauma Care Systems Planning and Development Act of 1990 to fund and support of public efforts for improving the national trauma management system had been issued. The Act was administered by Health Resources and Services Administration (HRSA) of the Department of Health and Human Services (DHHS). Under this program, a model trauma care system which was planed to use in trauma system development was written by a consensus panel of experts [14], when Congress failed to reauthorize resources for the program in 1995. It was funded again in FY2001 and 2002. Title XII of the PHSA is responsible for improving trauma and emergency medical care through system improvement. This goal is accomplished through: a) a grant program available to State EMS offices to improve the trauma care component of the EMS plan; b) a grant program to improve rural EMS care; and c) discretionary activities including research, evaluation, and grants for special EMS/trauma initiatives [15]. This study was based on the hypothesis that some patient data from all hospitals in a region/state are preferable to obtain more specific clinical data from a few TCs. This study aimed to a) determine the feasibility of using hospital discharge data to assess the performance of a statewide trauma system, b) examine whether differences in the distribution of high-risk pediatric trauma patients to TCs exist in a mandated trauma system compared to a non-mandated trauma system, c) provide a model for enthusiastic immature trauma systems transform to maturity, utilizing the study's results and recommendations.

\section{Materials and Methods}

A retrospective approach was advocated in order to achieve aim of this study. The investigators aimed to utilize a previous child trauma dataset (1999-2000), the time when Indiana trauma system had not yet moved to maturity, compare with data from Florida that had already been in maturity for more than 14 years, the time of this data [16]. Thereby, a review of hospital discharge data in Florida and Indiana of 14,537 pediatric trauma patients: 3478 from Indiana (non-mandated trauma system) (also a voluntary evolving system), and 11,059 from Florida (a mandated trauma system) was conducted. Although Indiana trauma system had not been mandated the tie of this analysis, major three TCs available in the state were taking preparatory steps toward accreditation by the ACS-TC consultation-verification program to help the state be recognized as a mandated trauma system. All traumatized children 1 - 15 years of age admitted to all hospitals, whether or not designated as level I/II TC in the two states were admitted to the study. Utilized hospital discharge data were obtained from the states' health departments, as well as states' hospital association. All discharge records with a principle International Classifi- 
cation of Disease, $9^{\text {th }}$ Revision, Clinical Modification (ICD-9) diagnosis code 800.00 to 959.9 ("Injury" or "Poisoning") [17], were initially included as "trauma cases." Infants less than one year of age were excluded, unless they were diagnosed as "child abuse" diagnosis with an E-code assigned; in which case they were considered one year old. The "abbreviated injury severity scale"-"injury severity score" (AIS-ISS) risk stratification technique using commercially available ICD-MAP90 software (Trianalytics, Inc., Baltimore, MD) was used to adjust for the differences in severity between Indiana and Florida patients. Our effort in this study was not mainly directed to gathering evidence to justify trauma system development, but to associating population-based and readily available data in two states at varying levels of trauma system development so as to identify norms, or benchmarks, of trauma system maturity.

The hospital discharge data analyzed included demographic, socioeconomic, payor status, diagnostic, surgical procedures, mechanism of injury, pattern of injury, and pre-existing co-morbidity. Principal risk factors included in the analysis were a) age (frequently categorized into: 1 to 5,6 to 10 , and 11 to 15 -y age strata), b) gender, c) pattern of injury (spleen, liver, pelvis, femur, spinal; cord injury, either isolated or combined with other organ injuries, as applicable), d) mechanism of injury, including motor vehicle accidents (MVA), falls, gun shot wounds (GSW), all other causes, and missing E-code categories recommended by the Centers for Disease Control and Prevention (CDC) [18], e) ISS from 1 to 75, which was further divided into $1-8,9-15,16-24$, and 25 or more categories, to describe mild, moderate, mild severity, and severe injuries. Children with an ISS $\geq 25$ were referred to as high risk or severely injured patients, f) selected interventional procedures (e.g., splenectomy, ventilation $\geq 4$ days, tracheostomy, g) hospital designation, which includes two observations: level I/II TC. Injury severity was assessed using the ISS measure concept [19] and its updated modification [20]. The ISS is based on the AIS [21] and its revised forms [22]. The AIS scale grades injury severity on an ordinal scale ranging from 1 (minor injury) to 6 (lethal injury, corresponding to ISS 75, see below) based on dividing the body into six anatomical regions (head and neck, face, thorax, abdomen, visceral pelvis, bony pelvis/extremities, and skin/external structures). The ISS, which ranges from 1 to 75 , is defined as the "sum squares of the highest AIS grade assigned to each of the three most severely injured body regions" (allowing only one injury per body region in computing for ISS). Being traumatized represents an "exposure" status, and having the positive observation of a variable of interest represents its positive outcome, while having its negative observation represents its negative outcome.

Statistical analysis: Comparisons and identify the strength of association between were performed, e.g. using chi-square $\left(X^{2}\right)$ test of independence (or Fisher's exact test, as appropriate), with ORs, together with their 95\% CIs to assess test stability. Mantel Haenszel summary OR (ORMH) was also used, as necessary, to provide a uniform risk assessment in case the OR for resultant two age strata were unequal. In testing the difference in the levels of the distributions of continuous variables, e.g., age, $t$-tests, or Mann Whitney $U$ non-parametric alternative were used, depending on the normality distribution of such variables. Our tolerable alpha error level was 0.05 ; results with a p-value $<0.05$ would be considered statistically significant.

\section{Results}

A total $11,059(34.5 / 100,000$ person-years) trauma admissions between 1 and 15 years of age with variable injury severities were reported in Florida, compared to 3478 (29.0/100,000 person-years) trauma admissions of the same age range in Indiana (Table 1). Our risk estimate has yielded an overall OR of 1.18 (CI 0.60, 2.4). The majority of pediatric trauma admissions were children with mild injuries (ISS 1 to 8$)(70 \%$ in Florida and $66 \%$ in Indiana, OR 1.2 , CI $1.1,1.3$. Only $4.0 \%$ of trauma patient admissions in Florida and $4.6 \%$ in Indiana insignificantly had an ISS of 25 or greater (Table 1). In Florida, $6000(54.3 \%)$ of pediatric trauma patients (all ISS categories) were admitted to trauma centers, compared to only $1398(40.2 \%)$ in Indiana (OR 1.8, CI 1.6, 1.9) (Table 2(a)). However, no significant difference was found in the distribution of all high risk children combined, regardless the TC/NTC setting in the two states who scored severe injuries [445 (4.0\%) in Florida vs. 160 (4.6\%), OR 0.87, CI 0.72, 1.05]. Likewise, Florida did not differ significantly from Indiana in the distribution of severely injured children (all ages combined) in the TC setting [349/445 (78.4) vs. 120/160 (75.5\%), OR 1.21$, CI $0.79,1.85]$.

Age-wise, there was no difference in the mean age among the two study subpopulations (11.0 years in Florida vs. 9.0 years in Indiana, Table 2(a)). The pattern of difference between both states in the distribution of severely injured patients by age was not consistently similar throughout the three age-category comparisons. For instance, the proportion of severe injuries among children 1 - 5 y was significantly lower among Florida patients $(21.3 \%)$ vs. $30.6 \%$ in Indiana (OR 0.62, CI 0.41 , 0.92 ), while no such difference was found in the other two age groups (Table 2(a)). When age-specific ORMH was compared with the crude OR for the distribution of all severely injured patients by state, age with a cutoff point of 5 years was not a confounding (crude OR 1.15, ORMH 1.12). Likewise, age was not a confounding in the other two age ranges (6 - 10 vs. other ages: crude OR 1.15, ORMH 1.15; and age 11 - 15 vs. other ages: crude 
Table 1. Pediatric trauma admissions by ISS category: Florida vs. Indiana.

\begin{tabular}{|c|c|c|c|c|c|c|}
\hline \multirow{3}{*}{ State population } & \multicolumn{2}{|c|}{ Florida } & \multicolumn{2}{|c|}{ Indiana } & \multirow[t]{2}{*}{ OR } & \multirow[t]{2}{*}{$\mathrm{CI}$} \\
\hline & \multicolumn{2}{|c|}{16 million } & \multicolumn{2}{|c|}{6.0 million } & & \\
\hline & $\mathrm{n}$ & Rate $^{*}$ & $\mathrm{n}$ & Rate $^{a}$ & & \\
\hline All trauma patients & 11,059 & 34.5 & 3478 & 29.0 & 1.18 & $0.60,2.4$ \\
\hline ISS category ${ }^{\mathrm{b}}$ & $\#$ & $\%$ & $\#$ & $\%$ & & \\
\hline 1 to 8 & 7702 & $70.0 \%$ & 2289 & $66.0 \%$ & 1.20 & $1.09,1.30$ \\
\hline 16 to 24 & 1039 & $9.4 \%$ & 420 & $12.1 \%$ & 0.76 & $0.67,0.85$ \\
\hline$\geq 25$ & 445 & $4.0 \%$ & 160 & $4.6 \%$ & 0.87 & $0.72,1.10$ \\
\hline
\end{tabular}

${ }^{\mathrm{a}}$ Rate: Per 100,000 Population/year; ${ }^{\mathrm{b}}$ Reference Category: Florida: Total Admissions = 11,059, Indiana: Total Admissions $=3478$.

Table 2. (a) Distribution of severely injured patients (ISS $\geq 25$ ) by sex, age, and injury mechanism; (b) Distribution of ISS $\geq$ 25 patients by TC/NTC, age, and cause of injury.

(a)

\begin{tabular}{|c|c|c|c|c|c|c|c|}
\hline \multirow{2}{*}{ All trauma patients } & \multicolumn{2}{|c|}{ Florida } & \multicolumn{2}{|c|}{ Indiana } & \multirow[b]{2}{*}{ OR } & \multirow[b]{2}{*}{$\mathrm{CI}$} & \multirow[b]{2}{*}{ p-value } \\
\hline & $\mathrm{n}$ & $\%$ & $\mathrm{n}$ & $\%$ & & & \\
\hline & 11,059 & $100.0 \%$ & 3478 & $100.0 \%$ & & & \\
\hline TC only (all ISS groups) & 6000 & $54.3 \%$ & 1398 & $40.2 \%$ & 1.80 & $1.60,1.90$ & \\
\hline ISS $\geq 25$ patients (TC \& NTC) & 445 & $4.0 \%$ & 160 & $4.6 \%$ & $0.87(\mathrm{a})$ & $0.72,1.05$ & \\
\hline Patients with ISS $\geq 25$ (TC only) & $349 / 445$ & $78.4 \%$ & $120 / 160$ & $75.5 \%$ & 1.21 & $0.79,1.85$ & \\
\hline Male & 298 & $67.0 \%$ & 101 & $63.0 \%$ & 1.30 & $0.65,8.3$ & \\
\hline Mean age $( \pm \mathrm{SD})$ y & $9.7 \pm 4.45$ & & $8.9 \pm 4.99$ & & & & 0.083 \\
\hline Median age & $11 \mathrm{y}$ & & $9 y$ & & & & \\
\hline Age $1-5 y$ & $95 / 445$ & $21.3 \%$ & $49 / 160$ & $30.6 \%$ & 0.62 & $0.41,0.92$ & \\
\hline Age $6-10 y$ & $123 / 445$ & $27.6 \%$ & $39 / 160$ & $24.4 \%$ & 1.19 & $0.87,1.80$ & \\
\hline Mechanism of injury (TC \&NTC) & $(445)$ & $100.0 \%$ & $(160)$ & $100.0 \%$ & & & \\
\hline MVA & 220 & $49.4 \%$ & 49 & $30.6 \%$ & 2.20 & $1.50,3.30$ & \\
\hline Fall & 32 & $7.2 \%$ & 4 & $2.5 \%$ & 3.00 & $1.10,8.70$ & \\
\hline GSW & 10 & $2.2 \%$ & 3 & $1.9 \%$ & 1.20 & $0.33,4.40$ & \\
\hline All other & 54 & $12.2 \%$ & 34 & $21.2 \%$ & 0.51 & $0.32,0.82$ & \\
\hline Total with E-code & 316 & $71.0 \%$ & 90 & $56.2 \%$ & 1.90 & $1.80,2.00$ & \\
\hline No E-code & $129 / 445$ & $29.0 \%$ & $70 / 160$ & $44.0 \%$ & 0.1 .9 & $1.80,2.00$ & \\
\hline
\end{tabular}

(a) OR ISS $\geq 25$ with Florida as a reference $=1 / 0.87=1.15$. This OR (1.15) was used in assessing confounding.

(b)

\begin{tabular}{|c|c|c|c|c|c|c|c|c|}
\hline & \multicolumn{4}{|c|}{ Trauma center $(\mathrm{TC})$} & \multicolumn{4}{|c|}{ Non-trauma-center (NTC) } \\
\hline & Florida & Indiana & p-value & & Florida & Indiana & p-value & \\
\hline Mean age $( \pm \mathrm{SD})$ & $9.82 \pm 4.42 y$ & $8.35 \pm 4.9 y$ & 0.007 & & $9.5 \pm 4.56 y$ & $10.85 \pm 4.76 y$ & 0.058 & \\
\hline Median age & $11 \mathrm{y}$ & $8 y$ & & & $10 \mathrm{y}$ & $13 \mathrm{y}$ & & \\
\hline Patient-ISS $\geq 25$ & $(349)$ & $(120)$ & OR & $\mathrm{CI}$ & (96) & (40) & OR & $\mathrm{CI}$ \\
\hline $1-5 y$ & $71 / 349(20.3 \%)$ & $43 / 120(35.8 \%)$ & 0.46 & $0.29,0.72$ & $24 / 96(25.0 \%)$ & $6 / 40(15.0 \%)$ & 1.89 & $0.71,5.10$ \\
\hline $11-15 y$ & $181 / 349(51.9 \%)$ & $47 / 120(39.2 \%)$ & 1.67 & $1.10,2.60$ & $46 / 96(47.9 \%)$ & $25 / 40(62.5 \%)$ & 0.55 & $0.26,1.17$ \\
\hline MVA & $190 / 349(54.4 \%)$ & $44 / 120(36.7 \%)$ & 2.06 & $1.34,3.63$ & $30 / 96(31.3 \%)$ & $5 / 40(12.5 \%)$ & 3.18 & $1.13,8.93$ \\
\hline Fall & $22 / 349(6.3 \%)$ & $3 / 120(2.5 \% 0$ & 2.60 & $0.77,8.93$ & $10 / 96(10.4 \%)$ & $1 / 40(2.5 \%)$ & 4.53 & $0.56,6,67$ \\
\hline GSW & $9 / 349(2.6 \%)$ & $0 / 120(0.0 \%)$ & 8.84 & $4.60,17.2$ & $1 / 96(1.0 \%)$ & $3 / 40(7.5 \%)$ & 0.13 & $0.01,1.29$ \\
\hline All Other & $29 / 349(8.3 \%)$ & $25 / 120(20.8 \%)$ & 0.34 & $0.19,0.60$ & $25 / 96(26.0 \%)$ & $9 / 40(22.5 \%)$ & 0.83 & $0.35,1.97$ \\
\hline No E-code & $99 / 349(28.4 \%)$ & $48 / 120(40 . \%)$ & 0.53 & $0.36,0.76$ & $30 / 96(31.3 \%)$ & $22 / 55(55.0 \%)$ & 2.69 & $1.26,5.74$ \\
\hline
\end{tabular}


OR 1.15, ORMH 1.15). There was no significant variation in sex distribution of the severely injured group (male $67 \%$ in Florida, 63\% in Indiana, OR 1.30, CI0.65, 8.3, Table 2(a)). The distribution of all mechanisms of injuries, but GSW, notably significantly differed. Florida experienced less prevalence of severe injuries with no E-code identification than Indiana (29\% vs. $44 \%$, OR 1.9 , CI 1.8, 2.0, Table 2(a)).

In the remaining number of patients who had E-code record, MVAs were the most predominant causes of injuries, that a highly-significant greater frequency of MVA-related severe injuries in Florida $(220 / 445=$ $49.4 \%$ vs. $49 / 160=30.6 \%$ ) in Indiana was noted (OR 2.2, CI $1.5,3.3)$. Florida children, too, significantly suffered greater frequency of severe injuries due to falls than Indiana's $(32 / 445=7.2 \%$ vs. $4 / 160=2.5 \%$, OR 3.0, 1.1 , 8.7). Conversely, Florida reported severe injuries related to "all other" traumata less commonly than Indiana $(54 / 445=12 \%$ vs. $34 / 160=21 \%$, OR 0.51 , CI 0.32 , $0.82)$.

Distribution by age and mechanism of injury (Table 2(b)) revealed that the odds for 1 - 5-year-old children at TC setting in Florida to have ISS $\geq 25$ was 0.46 , CI 0.29 , 0.72 compared to Indiana peers $(71 / 349=20.3 \%$ vs. $43 / 120=35.8 \%$ ). The other two age groups did not differ in the distribution of their ISS either as TC or NTC candidates. MVA injuries with ISS $\geq 25$ both among TCand NTC-children were reported more frequently in Florida than in Indiana $(54.4 \%$ vs. $36 \%$, OR 2.06 , CI 1.34, 3.63, Table 2(b)) (same behavior as in the collective comparison above, Table 2(a)). Also, GSW-severe injuries were more encountered by Florida TC patients of all ages combined $(2.6 \%$ vs. $0.0 \%$ Indiana, OR 8.84 , CI $4.60,17.2)$. No significant difference with the same regard among the NTC was detected. Child falls also did not have a significant difference, either at TC or NTC settings (Table 2(b)). Trauma center children in Florida had only 0.34 odds, CI $0.19-0.60$, of developing "all other" type of severe injuries in comparison with Indiana peers $(8.3 \%$ vs. $20.8 \%$, Table 2(b)). No such significant difference was found in the NTC comparison. Further, "no-E-code" incidents were less frequent among Florida severely injured children admitted to TCs in comparison to Indiana counterparts $(8.3 \%$ vs. $20.8 \%$, OR 0.53 , CI $0.35,0.76)$. A similar trend in the distribution of "noE-code" injury pattern was found in the NTC comparison (Florida $31.3 \%$ vs. Indiana 55.0\%, OR 2.96, CI 1.26, 5.74).

Distribution by age and mechanism of injury (Table 2(b)) revealed that the odds for 1-5-year old children at TC setting in Florida to have ISS $\geq 25$ was 0.46 , CI 0.29 , 0.72 compared to Indiana peers $(71 / 349=20.3 \%$ vs. $43 / 120=35.8 \%$ ). The other two age groups did not differ in the distribution of their ISS either as TC or NTC candidates. MVA injuries with ISS $\geq 25$ both among TC- and NTC-children were reported more frequently in Florida than in Indiana $(54.4 \%$ vs. $36 \%$, OR 2.06 , CI 1.34, 3.63, Table 2(b)) (same behavior as in the collective comparison above, Table 2(a)). Also, GSW-severe injuries were more encountered by Florida TC patients of all ages combined $(2.6 \%$ vs. $0.0 \%$ Indiana, OR 8.84 , CI $4.60,17.2)$. No significant difference with the same regard among the NTC was detected. Child falls also did not have a significant difference, either at TC or NTC settings (Table 2(b)). Trauma center children in Florida had only 0.34 odds, CI $0.19-0.60$, of developing "all other" type of severe injuries in comparison with Indiana peers $(8.3 \%$ vs. $20.8 \%$, Table 2(b)). No such significant difference was found in the NTC comparison. Further, "no-E-code" incidents were less frequent among Florida severely injured children admitted to TCs in comparison to Indiana counterparts $(8.3 \%$ vs. $20.8 \%$, OR 0.53 , CI $0.35,0.76)$. A similar trend in the distribution of "noE-code" injury pattern was found in the NTC comparison (Florida $31.3 \%$ vs. Indiana 55.0\%, OR 2.96, CI 1.26, 5.74).

The average ISS did not differ between the two states' high-risk patients either in a cohort $(31.7 \pm 11.13,30.6 \pm$ 9.6, $\mathrm{p}=0.232)$ or stratified by age $(1-5 \mathrm{y}: 30.5 \pm 11.6$ FL vs. $31.9 \pm 13.7 \mathrm{IN}, \mathrm{p}=0.535,6-10 \mathrm{y}: 34.0 \pm 13.3 \mathrm{FL}$ vs. $30.4 \pm 6.5 \mathrm{IN}, \mathrm{p}=0.097,11-157: 31.0 \pm 9.429 .8 \pm 7.4$ 0.310) (Table 3(a)).

Except for pelvic trauma, which comprises $16.2 \%$ of the high-risk trauma admissions in Florida and $7.5 \%$ in Indiana (OR 2.38, CI 1.30, 4.5), the other four injury patterns were not different (OR ranged from 0.79 to 1.53 , all confidence intervals contained one) (Table 3(a)). We also found that the frequencies of having certain comorbidities and/or complications were so small to non-existing at all among high risk patients with no significant variation (Table 3(a)), (none had pulmonary embolus, the reason why this complication was omitted from the analysis).

(It is important to notice that the presented injury pattern in Table 3(a) represents the number of observations each individual organ, spleen or liver, compartment, femur or pelvis, or tissue, spinal cord, was involved in). Pelvic injury in patients with ISS $\geq 25$ showed significant difference among children admitted to TCs (19.8\% Florida, 6.7\% Indiana, OR 3.5, CI 1.6, 7.4). No similar relationship was found among NTC patients (Table 3(b)).

\section{Discussion}

This study clearly demonstrates that a statewide administrative database can be used to describe the overall distributions of trauma patients over acute care and/or trauma center healthcare facilities whether or not a man dated trauma system exists. Statewide administrative database could also provide an important epidemiologic 
Table 3. (a) Distribution of ISS $\geq 25$ patients by mean ISS, age, injuries, and comorbidity; (b) Distribution of ISS $\geq 25$ patients by trauma/non-trauma centers, ISS, injury pattern.

(a)

\begin{tabular}{|c|c|c|c|c|c|c|}
\hline & \multicolumn{2}{|c|}{ Florida } & \multicolumn{3}{|c|}{ Indiana } & p-value \\
\hline Mean ISS for patients with ISS $\geq 25$ & \multicolumn{2}{|c|}{31.711 .13} & \multicolumn{3}{|c|}{$30.6 \pm 9.6$} & 0.232 \\
\hline $1-5 y$ & \multicolumn{2}{|c|}{$30.5 \pm 11.6$} & \multicolumn{3}{|c|}{$31.9 \pm 13.7$} & 0.535 \\
\hline $6-10 y$ & \multicolumn{2}{|c|}{$34.0 \pm 13.3$} & \multicolumn{3}{|c|}{$30.4 \pm 6.5$} & 0.097 \\
\hline $11-15 y$ & \multicolumn{2}{|c|}{$31.0 \pm 9.4$} & \multicolumn{3}{|c|}{$29.8 \pm 7.4$} & 0.310 \\
\hline & $\mathrm{n}$ & $\%$ & $\mathrm{n}$ & $\%$ & OR & $\mathrm{CI}$ \\
\hline All patients-ISS $\geq 25(n=605)$ & $(445)$ & $100.0 \%$ & $(160)$ & $100.0 \%$ & 0.87 & $0.72,1.05$ \\
\hline Spleen Injury $(\mathrm{n}=154))$ & 120 & $27.0 \%$ & 34 & $21.3 \%$ & 1.37 & $0.89,2.1$ \\
\hline Liver Injury $(n=61)$ & 49 & $11.0 \%$ & 12 & $7.5 \%$ & 1.53 & $0.79,2.9$ \\
\hline Pelvic Injury $(\mathrm{n}=84)$ & 72 & $16.2 \%$ & 12 & $7.5 \%$ & 2.38 & $1.30,4.5$ \\
\hline Femur Shaft Injury $(\mathrm{n}=54)$ & 38 & $8.5 \%$ & 16 & $10.0 \%$ & 0.84 & $0.46,1.6$ \\
\hline Spinal Cord Injury $(\mathrm{n}=29)$ & 20 & $4.5 \%$ & 9 & $5.6 \%$ & 0.79 & $0.35,1.8$ \\
\hline \multicolumn{7}{|l|}{ Comorbidity (ISS $\geq 25$ cases) } \\
\hline Bronchial Asthma $(\mathrm{n}=15)$ & 14 & $3.1 \%$ & 1 & $0.60 \%$ & 5.10 & $0.67,39.6$ \\
\hline Cardiac Arrest (17) & 11 & $2.5 \%$ & 6 & $3.80 \%$ & 0.65 & $0.24,1.8$ \\
\hline Hypertension $(n=7)$ & 4 & $0.9 \%$ & 3 & 1.95 & 0.48 & $0.11,2.14$ \\
\hline
\end{tabular}

NB. The total number of injuries may exceed the number of injured; some patients often have $>1$ injury at a time.

(b)

\begin{tabular}{|c|c|c|c|c|c|c|c|c|c|c|}
\hline & \multicolumn{5}{|c|}{ Trauma center $(\mathrm{TC})$} & \multicolumn{5}{|c|}{ Non-trauma center (NTC) } \\
\hline & FL & IN & & & & FL & IN & & & \\
\hline & $(349)$ & $(120)$ & OR & $\mathrm{CI}$ & p-value & (96) & $(40)$ & OR & $\mathrm{CI}$ & p-value \\
\hline Mean ISS $25-75$ y & $32.45 \pm 11.46$ & $30.57 \pm 9.07$ & & & 0.068 & $29.17 \pm 9.44$ & $30.53 \pm 11.25$ & & & 0.470 \\
\hline Mean ISS $1-5 y$ & $31.59 \pm 13.04$ & $31.16 \pm 13.21$ & & & 0.865 & $27.29 \pm 4.06$ & $36.83 \pm 18.9$ & & & 0.273 \\
\hline Mean ISS $6-10 y$ & $34.64 \pm 13.21$ & $31.50 \pm 6.85$ & & & 0.214 & $31.81 \pm 13.4$ & $26.56 \pm 3.25$ & & & 0.257 \\
\hline Mean ISS $11-15 y$ & $31.61 \pm 9.55$ & $29.43 \pm 5.17$ & & & 0.132 & $28.65 \pm 8.59$ & $30.44 \pm 10.58$ & & & 0.443 \\
\hline Spleen injury $($ all ages $=154)$ & $78 / 349(22.3 \%)$ & $21 / 120(17.5 \%)$ & 1.36 & $0.79,2.36$ & & $\begin{array}{c}42 / 96 \\
(43.8 \%)\end{array}$ & $13 / 40(32.5 \%)$ & 1.62 & $0.74,3.5$ & \\
\hline Liver injury $($ all ages $=61)$ & $41 / 349(11.7 \%)$ & $8 / 120(6.7 \%)$ & 1.86 & $0.85,4.10$ & & $8 / 96(8.3 \%)$ & $4 / 40(10.0 \%)$ & 0.818 & $0.23,2.9$ & \\
\hline Femur injury (all ages $=54$ ) & $35 / 349(10.0 \%)$ & $14 / 120(11.7 \%)$ & 0.84 & $0.44,1.63$ & & $3 / 96(3.1 \%)$ & $2 / 40(5.0 \%)$ & 0.613 & $0.09,3.8$ & \\
\hline Spinal cord injury $($ all ages $=29$ ) & $18 / 349(5.2 \%)$ & $9 / 120(7.5 \%)$ & 0.67 & $0.29,1.54$ & & $2 / 96(2.1 \%)$ & $0 / 40(0.0 \%)$ & 1.70 & $0.10,4.0$ & \\
\hline
\end{tabular}

NB. FL \& IN, (all ages): with ISS $\geq 25=349,120$. FL \& IN patients (all ages) in TCs and NTCs, ISS $\geq 25=96,40$, respectively.

profile of where the state's high-risk trauma patients are receiving care, when the patient distributions risks have been adjusted for using ISS grading. For instance, it could be identified that Florida trauma patients experience higher rate $(54 \%)$ of admission to TCs regardless of injury severity than Indiana $(40 \%)$. Whether this was a merit of mandated trauma system is debatable. This was not the case for high risk patients as almost three quarters of them in both states were admitted to TCs. This finding may reflect a first responder bias that injured children should go to TCs. Embracing a mandated trauma system provides appropriate environment both for policymakers 
and health practitioners to maintain quality service. As of the time of this study, Indiana was among the states that did not have such system, the absence of which may probably impact the behavior and the distribution (and probably the outcome) of childhood and adolescence trauma in its severest forms. The study also provides that children 1 - 15 years old with variable injury severities in Indiana were less likely to be treated at TCs as in Florida, although the two states did not vary in the frequency of developing severe injuries. Further, both severe injury populations did not vary in the frequency of selective admission to TCs. Both states' severely injured children have the same age average, with Indiana children less liable to MVA or falls. Indiana high risk patients were also less liable to pelvic injury either collectively or specified by being $11-15$ y old receiving care at any level I/II TCs. Alarmingly, the Indiana data registration system suffers missing E-code from the records of severely injured patients. This problem probably involves technical difficulties regarding electronic data input design, but it may also reflect a systemic malpractice when no mandated trauma-system standards to adhere to have been in action. Likewise, the dataset we were provided lacked some clinical information of evaluative benefit, e.g., pre-hospital time lapse until diagnosis, GCS score, mostly due to less comprehensive state trauma database.

The administrative databases used in this study present limitations that must be considered as they affect, in many cases, the ability to make and support strong conclusions from the data. For instance, there were some unexpected management differences in comparing mandated and non-mandated trauma systems that warrant additional analysis, probably using patient matching techniques to permit more exact comparisons between clinically and demographically similar patients. With those limitations in the use of statewide administrative data, this data source still provide sufficient information until more comprehensive statewide trauma registry dataset has been available. Moreover, analysis of the trauma data obtained from the statewide database can be important for continually evaluating and monitoring the progress and performance of both evolving and mature trauma systems. Further efforts should focus on developing guidelines for data abstraction so that more complete listing of injuries can be achieved for all patients [23].

\section{Conclusion}

Overall, despite these limitations encountered, aim of this study has been accomplished. First, the analysis could describe, specify, and compare the distribution of the multitude of variables under investigation across the two states. Having results in disagreement with what has been predicted does not undermine the value of current Indiana database. The latter could be the basis for more integrated database when resources have been directed to helping Indiana's trauma system reach maturity. The results obtained from this study provide model for enthusiastic health authorities, nationally and internationally, looking forward to improving their trauma service through "maturation", once the strategic plans and resources have been furnished. Authorities interested in investing in the development of their trauma systems, e.g., transforming to mandated systems, may benefit from the results of this study, e.g., compare child injury outcomes and impacts upon the public's health and national economies before and after such transformation.

\section{REFERENCES}

[1] M. Dowd, H. D. Kenan and S. L. Bratton, "Epidemiology and Prevention of Childhood Injuries," Critical Care Medicine, Vol. 30, No. 11, 2002, pp. S358-S392.

[2] F. J. Schodard and G. Saxe, "Ten-Year Research Review of Physical Injuries," Journal of the American Academy of Child and Adolescent Psychiatry, Vol. 40, No. 10, 2011, pp. 1128-1145.

[3] L. F. McCaig and C. W. Burt, "National Hospital Ambulatory Medical Care Survey: 2001 Emergency Department Summary. Advance Data from Vital and Health Statistics (US)," 2003.

http://www.cdc.gov/nchs/data/ad/ad358.pdf

[4] L. A. Fingerhut and M. Warner, "Injury Chart Book. Health United States, 1996-1997, Hyattsville (MD): National Center for Health Statistics,” 1997.

http://www.safetypolicy.org/pm/bkgd.htm

[5] J. Phelan, J, Khoury and H. Kalkwarf, "Residential Injuries in US Children and Adolescents," Public Health Reports, Vol. 120, No. 1, 2005, pp. 63-70.

[6] N. C. Mann, J. R. Hedges and R. Sandoval, "Trauma System Impact on Admission Site: A Comparison of Two states," Journal of Trauma, Vol. 46, No. 4, 1999, pp. 631637. doi:10.1097/00005373-199904000-00012

[7] Health Resources and Services Administration (HRSA), "A 2002 National Assessment of State Trauma System Development, Emergency Medical Services Resources, and Disaster Readiness for Mass Casualty Events: Table: Characteristics of Trauma Systems." http://www.hrsa.gov/trauma/survey.htm

[8] E. L. MacKenzie, D. Hoyt, J. C. Sacra, et al., "National Inventory of Hospital Trauma Centers," JAMA, Vol. 289, No. 2003, pp. 1515-1522.

[9] United States Census Bureau, "Census-2000 Demographic Profile Highlights,” 2002.

http://www.census.gov/main/www/cen2000.html

[10] Centers for Disease Control and Prevention (CDC), "US National Center for Injury Prevention and Control. Childhood Injury Fact Sheet: Injuries among Children and Adolescents," 2005. 
http:www.cecfd.gov/ncipc/factsheets/childh.htm http://books.google.com.eg/books?id=gaYtFuND7VIC\&p $\mathrm{g}=\mathrm{PA} 1754 \& \mathrm{dq}=$ Centers + for + Disease + Control + and + Prev ention

[11] Centers for Disease Control and Prevention (CDC) US, "Web-based Injury Statistics Query and Reporting System (WISQARS), Atlanta, GA: National Center for Injury Prevention and Control," 2003. http://www.cdc.gov/ncipc/wisquars

[12] National SAFE KIDS Campaign (NSKC), "Childhood Injury Fact Sheet," National SAFE KIDS Campaign, Washington, D.C., 2004. http://books.google.com.eg/books?id=gaYtFuND7VIC\&p $\mathrm{g}=\mathrm{PA} 1755 \& \mathrm{dq}=$ National + SAFE $+\mathrm{KIDS}+$ Campaign $+(\mathrm{NS}$ $\mathrm{KC})$

[13] G. J. Bazzoli, K. J. Madura, G. F. Cooper, E. J. MacKenzie and R. V. Maier, "Progress in the Development of Trauma Systems in the United States: Results of a National Survey," JAMA, Vol. 273, No. 5, 1995, pp. 395401. doi:10.1001/jama.1995.03520290047028

[14] R. R. Bass, S. P. Gainer and A. Carlini, "Update on Trauma System Development in the US," Journal of Trauma, Vol. 47, No. 3, 1999, pp. S15-21. doi:10.1097/00005373-199909001-00005

[15] R. J. Bonnie, C. E. Fulco and C. T. Liverman, "Reducing the Burden of Injury," National Academy Press, Washington, D.C., 1999.

[16] University of South Florida, "A Comprehensive Assessment of Florida Trauma System," 2005. http://www.doh.state.fl.us/demo/trauma/PDFs/Final_Trau ma_Assessment_Report.pdf
[17] Department of Health and Human Services (US) (DHHS), National Center for Health Statistics, "International Classification of Disease, $9^{\text {th }}$ Revision, Clinical Modification," Hyattsville (MD), DHHS, Pub. No. PHS, 80-1260. 1980. http://library.brown.edu

[18] Centers for Disease Control and Prevention (CDC), "US Recommended Framework for Presenting Injury Mortality Data," MMWR 46(RR 14), 1997, pp. 1-30.

[19] S. P. Baker, O’Neil and W. Haddon Jr., "The Injury Severity Score: A Method for Describing Patients with Multiple Injuries and Evaluating Emergency Care," Journal of Trauma, Vol. 14, No. 14, 1974, pp. 187-96. doi:10.1097/00005373-197403000-00001

[20] T. Osler, S. P. Baker and W. Long, "A Modification of the Injury Severity Score (ISS) That Both Improves Accuracy and Simplifies Scoring," Journal of Trauma, Vol. 43, No. 6, 1997, pp. 922-5. doi:10.1097/00005373-199712000-00009

[21] Committee on Medical Aspects of Automotive Safety, "Rating the Severity of Tissue Damage. The Abbreviated Scale," JAMA, Vol. No. 215, 1971, pp. 277-280.

[22] American Medical Association for Automotive Medicine, "The Abbreviated Scale-1985 Revision, Des Plaines," 1985. http://books.google.com.eg/books/about/Abbreviated_inj ury_scale.html?id=huMhAQAAMAAJ\&redir_esc=y

[23] R. J. Mullins, J. Veum-Stone and J. R. Hedges, "An Analysis of Hospital Discharge Index as a Trauma Data Base," Journal of Trauma, Vol. 39, No. 5, 1995, pp. 941948. doi:10.1097/00005373-199511000-00020 